\title{
Does metformin usage improve survival in head and neck squamous cell carcinoma? A population-based study
}

\author{
Alexandra E. Quimby ${ }^{1 *}$ (D), Nicole L. Lebo ${ }^{1}$, Rebecca Griffiths ${ }^{2}$, Stephen Hall ${ }^{3}$, Jim Dimitroulakos ${ }^{4}$ and \\ Stephanie Johnson-Obaseki
}

\begin{abstract}
Background: We sought to expand upon preliminary data suggesting that metformin confers a survival benefit to patients with head and neck squamous cell carcinoma (HNSCC).

Methods: A large-scale retrospective cohort study of all patients in Ontario diagnosed with squamous cancer of the larynx, hypopharynx, and nasopharynx between Dec 1st 2007 to Dec 1st 2012 was undertaken. The Institute for Clinical and Evaluative Sciences was accessed to obtain patient demographic, treatment and outcome information. We included patients on metformin at the time of diagnosis. Kaplan Meier methods and Cox Regression models were used.

Results: Patients taking metformin at the time of diagnosis had a higher comorbid status but were otherwise similar to patients without metformin usage. Using multivariate analysis, neither overall survival nor disease specific survival was improved in patients on metformin (OS: HR 1.123, $p=.338$; DSS: HR 1.048, $p=.792$ ).

Conclusions: No survival advantage was observed in patients with HNSCC taking metformin at the time of diagnosis.

Keywords: Squamous cell carcinoma, Metformin, Larynx, Hypopharynx, Nasopharynx
\end{abstract}

\section{Introduction}

Head and neck squamous cell carcinoma (HNSCC) accounts for approximately $6 \%$ of all new cases of cancer in Canada $[1,2]$. Over the past two decades, Human Papillomavirus (HPV) has emerged as an independent etiologic factor for HNSCC. As a result, epidemiologic trends have shifted towards increased incidence, younger age at diagnosis, and overall improved survival of HNSCC [3]. However, outcomes for patients with non-HPV associated HNSCC remain poor. Treatment of HPV-negative HNSCC can be challenging, and is met with considerable patient morbidity. For cancers of the larynx, hypopharynx, and nasopharynx - three subsites in which HNSCC is uncommonly attributed to HPV infection - treatment can consist of either primary surgery

\footnotetext{
* Correspondence: Aquim047@uottawa.ca

${ }^{1}$ Department of Otolaryngology, Head and Neck Surgery, University of Ottawa, 501 Smyth Rd, Module S - Room M2566, Box 216, Ottawa, ON K1H 8L6, Canada

Full list of author information is available at the end of the article
}

(in the case of larynx and hypopharynx), primary radiotherapy (early laryngeal cancers), or chemoradiotherapy (nasopharynx or advanced larynx/hypopharynx). Surgical morbidity at these sites can be high, and toxicities from chemoradiotherapy are common, and can significantly impact patients' quality of life [4-7].

There has recently been an impetus for the discovery of effective targeted, novel adjuvant therapeutic agents for the treatment of HNSCC [8]. Epidermal growth factor (EGFR) inhibitors (cetuximab, gefitinib, erlotinib) have demonstrated early promise in the treatment of HNSCC [9-13]. The use of statins has also recently been shown to improve overall- and disease-specific survival in patients with HPV-negative HNSCC [14-16]. Combination novel therapeutics have also shown promise, for example, Monenisin - an animal antibiotic - has been shown to enhance the cytotoxicity of both erlotinib and lovastatin in vivo [17]. Despite the promise suggested by these targeted agents, though, they have made less of an impact on the survival outcomes in HNSCC to date than

(c) The Author(s). 2018 Open Access This article is distributed under the terms of the Creative Commons Attribution 4.0 International License (http://creativecommons.org/licenses/by/4.0/), which permits unrestricted use, distribution, and 
initially hypothesized. An ongoing need for the discovery of effective, targeted agents for the treatment of HNSCC exists.

Metformin is a biguanide oral antihyperglycemic used in the treatment of type 2 diabetes mellitus. Diabetics are known to have an increased risk of total body cancer, with hyperinsulinemia and hyperglyceimia proposed as carcinogenic mechanisms [18-20]. Metformin has insulin-sensitizing and glucose-lowering effects via a pathway that involves the activation of AMP-activated protein kinase (AMPK) [21, 22]. Additional downstream effects of AMPK target phosphorylation include inhibition of cellular growth and proliferation under stress conditions [23-25]. Through activation of AMPK in human carcinoma cells, metformin inhibits clonal survival in vitro, and enhances the effects of ionizing radiation on these cells [26]. It has been shown to enhance radiation effects on head-and-neck cancer cell lines in both in vivo and in vitro models [27]. Several observational studies in humans have also supported an anti-tumorigenic effect of metformin, correlating metformin use in diabetics with decreased cancer incidence and mortality, and improved treatment response in colorectal and breast cancers [28-34]. In patients with cancer of the larynx, a recent single-centre study demonstrated improved survival in diabetics taking metformin compared with diabetics not on metformin [35]. This preliminary evidence, taken together with the minimal side-effect profile of metformin, make it an appealing potential adjuvant treatment for HNSCC [36].

On the basis of this growing body of evidence, we conducted a large-scale retrospective cohort study to determine whether HNSCC patients taking metformin have a survival advantage compared with patients not on metformin. To account for the fact that HPV status is not routinely recorded for all HNSCC, and to control for the confounding effects of HPV-positivity on HNSCC survival, we selected only cases of HNSCC in subsites where HPV is rarely the predominant etiologic agent: the larynx, nasopharynx, and hypopharynx [4-6, 37, 38].

\section{Methods}

\section{Data sources and patient population}

A population-based retrospective cohort study was performed using data sources retrieved from electronic databases maintained at the Institute for Clinical Evaluative Sciences (ICES), where patient data is linked between databases using unique encoded identifiers.

The source of our patient population was The Ontario Cancer Registry, which includes all incident cases of cancer in Ontario. We identified all patients over the age of 65.5 diagnosed with nasopharynx, hypopharynx, or larynx malignancy between January 1, 2007 - December 31, 2012. We excluded patients previously diagnosed with HNSCC within 10 years prior to their present diagnosis date.

Our cohort was linked to the Ontario Drug Benefit Database (ODB) and divided into patients who were taking metformin at the time of diagnosis of HNSCC and those who had no metformin exposure. The ODB database includes claims from all patients eligible for the Ontario Drug Benefit Program. Eligibility is limited to those with a valid card for Ontario's universal, publicallyfunded healthcare system - the Ontario Health Insurance plan (OHIP) - who are $\geq 65$ years of age, and patients enrolled in other specialized programs. We excluded control patients who had exposure to metformin within a year prior to or after their diagnosis. Primary analysis was conducted with metformin use being defined as the patient taking metformin at the time of diagnosis of malignancy. Secondary analyses were performed to assess whether duration of metformin use impacted results, with the definition of metformin use adjusted to, (a) metformin use for a minimum of 1 year prior to diagnosis and 4 months after diagnosis, and, (b) metformin use for a minimum of 1 month prior to diagnosis and 4 months after diagnosis. For secondary analyses, case and control patients that died within 4 months of their diagnosis were excluded.

\section{Covariates}

Identified patients were classified into one of six treatment groups: 1) primary surgery with or without adjuvant radiation and/or chemotherapy, 2) primary radiation therapy (RT) with or without adjuvant/ salvage surgery, 3) primary combined chemoradiotherapy (CRT) with or without adjuvant/ salvage surgery, 4) induction chemotherapy before radiotherapy, 5) palliative/ no treatment, or 6) other therapies not captured by the aforementioned groups. Surgeries were identified through two means: The Canadian Institute for Health Information (CIHI) database, which contains all hospital discharge records, and The OHIP Claims database, which captures physician billing records. Patients were classified as having undergone primary surgery if they underwent pharyngo-laryngectomy or "total excision" of the glottis, supraglottis, or larynx, defined by the following ICD10 Procedure codes - 1GA89, 1GB89, 1GE89, 1GE91 - and OHIP fee codes- M081, S068 within 4 months of diagnosis [39]. Glottic cancer patients who had partial surgeries or biopsies as their only treatment were also classified in the primary surgery group. Radiotherapy and chemotherapy treatments were abstracted from the Cancer Care Ontario's Activity Level Reporting (ALR) Database. A patient was considered to have had curative radiotherapy if they were administered a total dose of $\geq 5000$ centigray (cGy) in $\geq 20$ total fractions to the relevant head and neck region within 4 months of diagnosis. A patient was categorized as receiving CRT if the chemotherapy started no more than 30 days prior to the initiation of 
radiotherapy. Any patient who received chemotherapy starting prior to this cutoff was classified in the induction chemotherapy group. Any patient who had RT to the head and neck at a palliative dose, received chemotherapy alone, or received no treatment at all within the first 4 months was classified in the palliative/ no treatment group. All other treatment regiments were classified as 'other'. All patients classified as having undergone palliative/ no treatment, 'other' treatments, or induction chemotherapy before radiotherapy were excluded from survival analyses.

Comorbidity was calculated based on the Elixhauser Comorbidity Index [40-42]. Hospital admissions within 5 years prior to diagnosis, abstracted from the CIHI Database, were used to calculate the comorbidity score. The Elixhauser score ranges from 0 to 31 based on 31 possible comorbid diagnoses. All diagnosis types were included in the calculations. Patients were categorized as receiving a score of $0,1,2$, or $3+$.

Demographic information for our cohort was retrieved from the Registered Persons Database (RPDP) supplied by the Ministry of Health and Long-term care. This dataset contains demographic information on anyone who has ever had an OHIP card number.

\section{Outcomes}

The Office of the Registrar General Database (ORGD) was used to retrieve vital status and cause of death information to determine overall survival (OS) and diseasespecific survival (DSS) for each patient. Information on vital status was available until March 31, 2015, and cause of death was available up to Dec 31, 2013.

\section{Statistical analysis}

SAS Software (Version 9.4, SAS Institute, Cary, NC, USA) was the statistical software used. We compared the distribution of demographics, treatments, and site between metformin users and non-users using the chi-square ( $\mathrm{X}[2])$ test for categorical variables and $\mathrm{t}$-test/ ANOVA (one-way analysis of variance) for continuous variables. Survival curves and log-rank scores were produced using the method of Kaplan and Meir [43]. To evaluate the survival benefit of metformin, we used Cox proportional hazards models to calculate hazards ratios (HR) with 95\% confidence intervals (CI). Age, gender, treatment regimen, comorbidity, and cancer site were controlled for in multivariate models. All variables were analyzed as categorical variables. A $p$-value of $<0.05$ was deemed statistically significant.

\section{Results}

A total of 1679 patients (metformin users and nonusers) were identified from the linked OCR and ODB databases. This included 208 patients taking metformin at the time of diagnosis of HNSCC in the sites under investigation, and 1471 matched control patients who had not had any exposure to metformin within at least 1 year before and after their date of diagnosis. A total of 448 patients (43 metformin users, 405 non-users) were excluded for having undergone no treatment, 'other' treatments, or induction chemotherapy followed by radiation. After these exclusions, there were a total of 1231 patients. Of these, there were 165 taking metformin at the time of diagnosis of HNSCC, and 1066 who had not had any exposure to metformin within at least 1 year before or after their date of diagnosis. Demographic and clinical characteristics of all included patients (metformin users and non-users) are detailed in Table 1. As expected, Elixhauser comorbidity score was significantly different between those taking metformin at the time of diagnosis (namely, diabetic patients) and metformin non-users, with those taking metformin having significantly higher Elixhauser scores, indicating a greater average number of comorbid diseases. Otherwise, no significant differences existed between those using and not using metformin with regards to age, gender distribution, treatment type, and site of primary malignancy. Glottic larynx was the most common HNSCC subsite in both subgroups of patients.

The Kaplan-Meier survival curve comparing OS between metformin users and non-users is displayed in Fig. 1. There was no significant difference in OS between patients taking metformin at the time of diagnosis and patients who had not had exposure to metformin for $\geq 1$ year before and after their diagnosis of $\operatorname{HNSCC}(p=0.9182)$.

The Kaplain-Meier survival curve comparing DSS for patients taking and not taking metformin at the time of diagnosis is displayed in Figs. 2. Similarly, there was no significant difference in DSS between metformin users and non-users $(p=0.9918)$.

Results from multivariate analysis of covariates for OS are summarized in Table 2. Covariates associated with significantly reduced OS included: increasing age - all age groups $>75$ demonstrated a statistically significant decrease in OS compared with age group 65-69, with increasing hazard ratio (HR) for each increase in age group - Elixhauser comorbidity score of 3+ (HR 1.902, 95\% CI [1.524-2.375]), and primary cancer of the hypopharynx or supraglottic larynx (hypopharynx: HR 2.933, 95\% CI [2.336-3.683]; supraglottic larynx: HR 2.296, 95\% [CI 1.867-2.825]) compared to patients with primary malignancy of the glottic larynx. Metformin use was not associated with a significant difference in OS compared to those not taking metformin $(p=0.4314$, HR 1.104, 95\% CI [0.863-1.413]).

Results from multivariate analysis of covariates for DSS are summarized in Table 3. Metformin use was not associated with a significant improvement in DSS $(p=0.9980$, HR 1.000, 95\% CI [0.695-1.440]). 
Table 1 Demographic and clinical characteristics of metformin use and non-use groups

\begin{tabular}{|c|c|c|c|c|}
\hline Variable & Category & $\begin{array}{l}\text { Cases (Metformin at } \\
\text { time of diagnosis) }\end{array}$ & $\begin{array}{l}\text { "Controls" (No metformin for } \geq 1 \text { year } \\
\text { prior and } \geq 1 \text { year after diagnosis) }\end{array}$ & $P$-value \\
\hline N & & 165 & 1066 & \\
\hline \multicolumn{5}{|l|}{ Age } \\
\hline & $65-69$ & $38(23.0 \%)$ & $280(26.3 \%)$ & \multirow[t]{6}{*}{0.874} \\
\hline & $70-74$ & 49 (29.7\%) & $289(27.1 \%)$ & \\
\hline & $75-79$ & $44(26.7 \%)$ & $257(24.1 \%)$ & \\
\hline & $80-84$ & $25(15.2 \%)$ & $168(15.8 \%)$ & \\
\hline & $85-90$ & $6(3.6 \%)$ & $52(4.9 \%)$ & \\
\hline & $=>90$ & $3(1.8 \%)$ & $20(1.9 \%)$ & \\
\hline Mean age at diagnosis $( \pm S D$ ) & & $74.55 \pm 6.09$ & $74.51 \pm 6.35$ & 0.934 \\
\hline \multicolumn{5}{|c|}{ Elixhauser Comorbidity Index Score } \\
\hline & 0 & $43(26.1 \%)$ & $637(59.8 \%)$ & \multirow[t]{4}{*}{$<0.001$} \\
\hline & 1 & $40(24.2 \%)$ & $197(18.5 \%)$ & \\
\hline & 2 & $30(18.2 \%)$ & $96(9.0 \%)$ & \\
\hline & $3+$ & $52(31.5 \%)$ & $136(12.8 \%)$ & \\
\hline \multicolumn{5}{|l|}{ Gender } \\
\hline & Female & $24(14.5 \%)$ & $175(16.4 \%)$ & \multirow[t]{2}{*}{0.543} \\
\hline & Male & $141(85.5 \%)$ & $891(83.6 \%)$ & \\
\hline \multicolumn{5}{|l|}{ Treatment type } \\
\hline & Surgery+/-RT/CRT & $31(18.8 \%)$ & $266(25.0 \%)$ & \multirow[t]{3}{*}{0.058} \\
\hline & RT+/-Surgery & $116(70.3 \%)$ & $646(60.6 \%)$ & \\
\hline & CRT+/-Surgery & $18(10.9 \%)$ & $154(14.4 \%)$ & \\
\hline \multicolumn{5}{|l|}{ Primary site } \\
\hline & Glottic larynx & $105(63.6 \%)$ & $656(61.5 \%)$ & \multirow[t]{4}{*}{0.406} \\
\hline & Hypopharynx & $17(10.3 \%)$ & $152(14.3 \%)$ & \\
\hline & Nasopharynx & $12(7.3 \%)$ & $55(5.2 \%)$ & \\
\hline & Supraglottic larynx & $31(18.8 \%)$ & $203(19.0 \%)$ & \\
\hline
\end{tabular}

$S D$ Standard deviation, $R T$ radiotherapy, CRT concurrent chemoradiotherapy

Secondary analyses were performed in order to determine whether duration of metformin use impacted results. These were performed with adjusted case definitions of: (a) metformin use for a minimum of 1 year prior to diagnosis and a minimum of 4 months after diagnosis, and, (b) metformin use for a minimum of 1 month prior to diagnosis and a minimum of 4 months after diagnosis. These analyses were treated as secondary analyses as there is an inherent survival bias for those patients remaining on metformin after treatment (only patients who remained alive long enough to receive metformin after treatment could be examined). For each of these, there was no significant effect of metformin use on OS or DSS when compared to control patients not taking metformin for a minimum of 1 year before and 1 year after the time of diagnosis. (Additional file 1: Table S1, Additional file 2: Table S2, Additional file 3: Table S3 and Additional file 4: Table S4). In the first secondary analysis in which cases were defined as metformin use for a minimum of 1 year prior to and 4 months after diagnosis, after taking into account the aforementioned exclusions, 95 cases and 1011 metformin non-users were identified. There was no significant difference in OS $(p=3610$, HR $1.168,95 \%$ CI $[0.837-1.630])$ or DSS ( $p=0.6822$, HR $0.902,95 \%$ CI [0.549-1.480]) between cases and metformin non-users. In the second scenario, in which cases were defined as metformin use for a minimum of 1 month prior to and 4 months after diagnosis, after taking into account the aforementioned exclusions, 118 cases and 1018 non-users were identified. There was again no significant difference in OS $(p=3639$, HR $1.150,95 \%$ CI $[0.850=1.557])$ or DSS $(p=0.9709$, HR 0.991, 95\% CI [0.623-1.578]).

\section{Discussion}

Metformin has demonstrated anti-tumorigenic effects both in vitro and in vivo, and has been shown to 


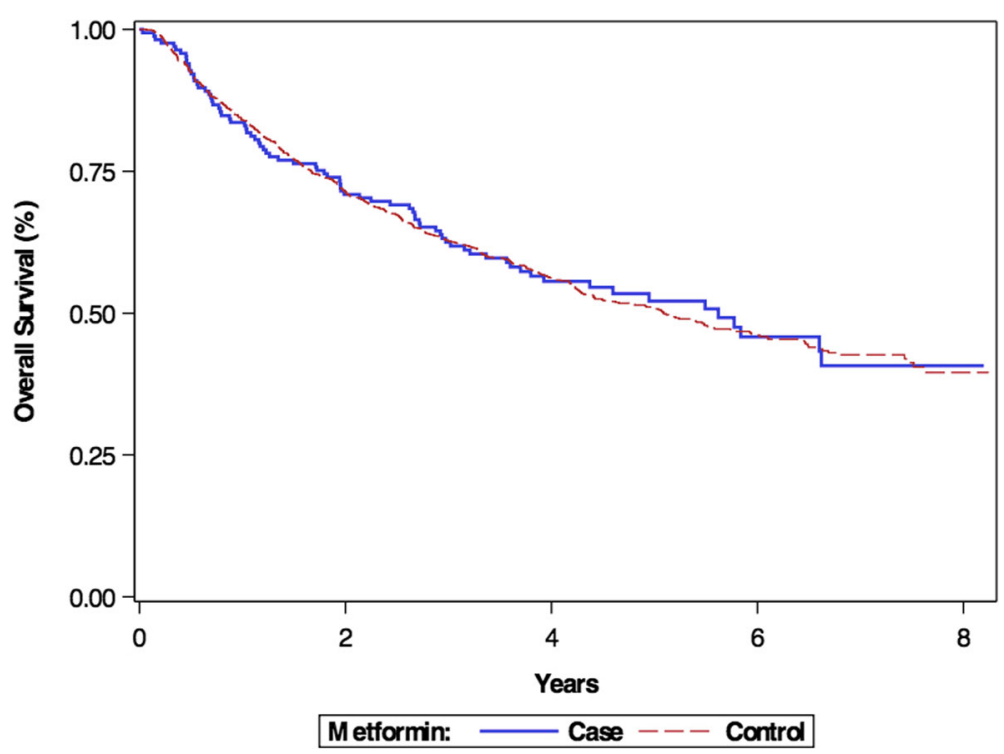

Fig. 1 Kaplan Meier curve demonstrating overall survival of metformin users vs. non-users $(p=0.9182)$

improve treatment response in breast and colorectal cancers [26-32]. Metformin's mechanism of action, biologically plausible mechanism of tumor suppression, and minimal side-effect profile make it an appealing anti-cancer therapy. While preliminary data exists suggesting that metformin may improve survival in patients with HNSCC of the larynx [35], our large-scale analysis has shown that no survival benefit exists from the use of metformin in squamous cell cancer of the larynx, nasopharynx, or hypopharynx. The data used in our multivariate analysis was compiled from all patients in Ontario diagnosed with these cancers over a 5 -year period.
There have been several animal studies and one retrospective study in humans suggesting that metformin may improve survival outcomes for HNSCC patients [44]. Sandulache et al. conducted a large-scale retrospective cohort study to examine the association between metformin use and improved survival in cancers of the larynx [35]. In multivariate analysis, they demonstrated improved OS $(p=0.04)$ when comparing diabetics using metformin to diabetics not on metformin. However, they did not demonstrate an improvement in either OS or DFS when they compared non-diabetics to diabetics using metformin. It is difficult to determine if

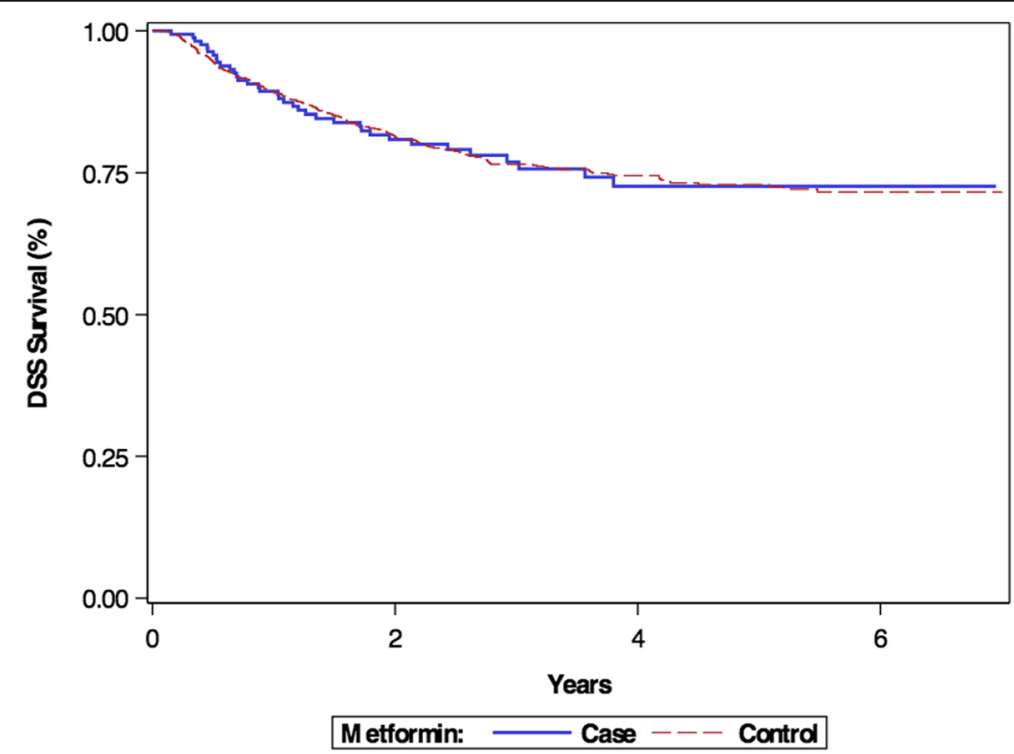

Fig. 2 Kaplan Meier curve demonstrating disease-specific survival of metformin users vs. non-users $(p=0.9918)$ 
Table 2 Multivariate regression analysis for overall survival (OS) in patients taking metformin at the time of diagnosis

\begin{tabular}{|c|c|c|c|c|c|}
\hline Covariate & Category & Comparator & $P$-value & Hazard Ratio & $95 \% \mathrm{Cl}$ \\
\hline \multicolumn{6}{|l|}{ Age } \\
\hline & $70-74$ & \multirow[t]{5}{*}{$65-69$} & 0.2574 & 1.152 & $0.902-1.471$ \\
\hline & $75-79$ & & $<.0001$ & 1.879 & $1.485-2.379$ \\
\hline & $80-84$ & & $<.0001$ & 2.309 & $1.776-3.001$ \\
\hline & $85-90$ & & $<0.001$ & 2.257 & $1.545-3.298$ \\
\hline & $=>90$ & & $<.0001$ & 4.457 & $2.614-7.599$ \\
\hline \multicolumn{6}{|l|}{ Gender } \\
\hline & Male & Female & 0.2969 & 1.124 & $0.903-1.399$ \\
\hline \multicolumn{6}{|c|}{ Treatment type } \\
\hline & CRT+/-surgery & \multirow[t]{2}{*}{$\mathrm{RT}+/$ - surgery } & 0.6839 & 1.053 & $0.821-1.350$ \\
\hline & Surgery+/-RT/CRT & & 0.7389 & 1.034 & $0.851-1.256$ \\
\hline \multicolumn{6}{|c|}{ Elixhauser Comorbidity Index Score } \\
\hline & 1 & \multirow[t]{3}{*}{0} & 0.1105 & 1.194 & $0.960-1.484$ \\
\hline & 2 & & 0.0618 & 1.298 & $0.987-1.708$ \\
\hline & $3+$ & & $<.0001$ & 1.902 & $1.524-2.375$ \\
\hline \multicolumn{6}{|c|}{ Primary site } \\
\hline & Hypopharynx & \multirow[t]{3}{*}{ Glottic larynx } & $<.0001$ & 2.933 & $2.336-3.683$ \\
\hline & Nasopharynx & & 0.0101 & 1.679 & $1.131-2.492$ \\
\hline & Supraglottic larynx & & $<.0001$ & 2.296 & $1.867-2.825$ \\
\hline \multicolumn{6}{|c|}{ Metformin use } \\
\hline & Control (no metformin exposure) & $\begin{array}{l}\text { Case (metformin use at } \\
\text { time of diagnosis) }\end{array}$ & 0.4314 & 1.104 & $0.863-1.413$ \\
\hline
\end{tabular}

$\mathrm{Cl}$ confidence interval, $R T$ radiation therapy, $C R T$ concurrent chemoradiation therapy

the improved survival in diabetics on metformin compared to diabetics not on metformin (which could include diabetics with complications such as nephropathy precluding metformin use) is actually representative of less severe diabetes in the metformin group rather than an improvement in survival as a result of metformin use. It stands to reason that those with more severe diabetes would have predictably worse OS compared with those whose sugars are controlled with the use of metformin. Our results are similar to Sandulache et al. in that when they compared non-diabetic metformin users to diabetics on metformin, they did not demonstrate an improvement in OS or DFS.

Limitations of our study include its retrospective design; a prospective study would be required in order to more rigorously assess for a survival advantage. The timeline of our study is such that survival data was available for all patients for a minimum of 3 full years following cancer diagnosis. We were therefore able to assess for changes in survival within this time-frame, but not long-term (five-year) survival for all patients in our cohort. We were unable to capture patients' tumor/ node/ metastases (TNM) cancer staging at time of diagnosis. For cancers of the larynx and hypopharynx, we were able to infer staging based on treatment received - the distribution of which was equal between case and control groups - since treatment is largely stage-specific and is uniform across centres. Though stage-specific treatment protocols for nasopharygeal cancer may vary more across centres, it can also be argued that staging variability should not have been significantly different between case and control groups, since the decision to be on metformin at the time of HNSCC diagnosis is unrelated to cancer stage. We captured data relating to whether patients were taking metformin at the time of their cancer diagnosis, but could not ensure that they continued to use metformin throughout the study period; however, secondary analyses examining metformin use over alternative time periods similarly did not show significant results. We were also unable to capture data regarding smoking and alcohol history, as these are not available in our data sources. We also did not have data related to patient baseline performance status. As well, our study specifically assessed for a survival advantage of metformin use in patients with HPV-negative head and neck cancers. Since HPV status is not conventionally reported in most databases, including the data sources available to us, and due to its confounding effects on head and neck cancer survival, we focused our analysis on patients with cancers of the larynx, 
Table 3 Multivariate regression analysis for disease specific survival (DSS) in patients taking metformin at time of diagnosis

\begin{tabular}{|c|c|c|c|c|c|}
\hline Covariate & Category & Comparator & $P$-value & Hazard Ratio & $95 \% \mathrm{Cl}$ \\
\hline \multicolumn{6}{|l|}{ Age } \\
\hline & $70-74$ & \multirow[t]{5}{*}{$65-69$} & 0.8138 & 0.958 & $0.673-1.364$ \\
\hline & $75-79$ & & 0.0035 & 1.636 & $1.175-2.277$ \\
\hline & $80-84$ & & 0.0067 & 1.726 & $1.163-2.561$ \\
\hline & $85-90$ & & 0.0450 & 1.793 & $1.013-3.175$ \\
\hline & $=>90$ & & 0.0275 & 2.832 & $1.122-7.148$ \\
\hline \multicolumn{6}{|l|}{ Gender } \\
\hline & Male & Female & 0.1428 & 1.283 & $0.919-1.791$ \\
\hline \multicolumn{6}{|c|}{ Treatment type } \\
\hline & CRT+/-surgery & \multirow[t]{2}{*}{$\mathrm{RT}+/$ - surgery } & 0.2510 & 1.218 & $0.870-1.704$ \\
\hline & Surgery+/-RT/CRT & & 0.1351 & 1.247 & $0.933-1.667$ \\
\hline \multicolumn{6}{|c|}{ Elixhauser Comorbidity Index Score } \\
\hline & 1 & \multirow[t]{3}{*}{0} & 0.8172 & 1.040 & $0.743-1.457$ \\
\hline & 2 & & 0.3511 & 1.218 & $0.805-1.842$ \\
\hline & $3+$ & & 0.0078 & 1.582 & $1.128-2.218$ \\
\hline \multicolumn{6}{|c|}{ Primary site } \\
\hline & Hypopharynx & \multirow[t]{3}{*}{ Glottic larynx } & $<.0001$ & 4.488 & $3.269-6.162$ \\
\hline & Nasopharynx & & $<0.001$ & 2.957 & $1.757-4.977$ \\
\hline & Supraglottic larynx & & $<.0001$ & 2.993 & $2.189-4.093$ \\
\hline \multicolumn{6}{|c|}{ Metformin use } \\
\hline & Control (no metformin exposure) & $\begin{array}{l}\text { Case (metformin use at } \\
\text { time of diagnosis) }\end{array}$ & 0.9980 & 1.000 & $0.695-1.440$ \\
\hline
\end{tabular}

$\mathrm{Cl}$ confidence interval, $R T$ radiation therapy, $C R T$ concurrent chemoradiation therapy

hypopharynx, and nasopharynx, which are typically HPV-negative cancers. We drew patient causes of death from the Office of the Registrar General Database (ORGD), where this information is extracted from death certificates. As death certificates are manually completed by physicians at the time of patient death, when there are often multiple disease processes at play, documented causes of death are not always reliable or replicable. This has the potential to impact our calculation of disease-specific survival. However, this would likely affect our calculation of DSS for both metformin users and non-users in a similar manner, since baseline demographic variables for both these groups were similar. Another inherent limitation in a study like ours is that it is impossible to exactly replicate the underlying disease states in the study and metformin non-use groups. The main indication for metformin treatment is diabetes and as such, comparing those on metformin to those not on metformin has the inherent difference that those patients on metformin will have underlying diabetes, contributing to a distinctly different disease state from those without.

\section{Conclusion}

Our large scale retrospective cohort study demonstrated that patients taking metformin at the time of diagnosis of squamous cell carcinoma of the larynx, hypopharynx, and nasopharynx do not have improved survival compared with those not on metformin. This negative finding, which is in contrast to prior studies, highlights the need for further analysis in the form of a large-scale prospective study in order to reach a definitive conclusion. We would encourage such a study, as metformin's biologically plausible mechanism of action and paucity of side effects make it an appealing and potentially efficacious novel therapeutic agent.

\section{Additional files}

Additional file 1: Table S1. Multivariate regression analysis for overall survival (OS) in patients taking metformin for at least 1 year before diagnosis and 4 months after diagnosis. (DOCX $18 \mathrm{~kb}$ )

Additional file 2: Table S2. Multivariate regression analysis for disease specific survival (DSS) in patients taking metformin for at least 1 year before diagnosis and 4 months after diagnosis. (DOCX 18 kb) 
Additional file 3: Table S3. Multivariate regression analysis for overall survival (OS) in patients taking metformin for at least 1 month before diagnosis and 4 months after diagnosis. (DOCX 19 kb)

Additional file 4: Table S4. Multivariate regression analysis for disease specific survival (DSS) in patients taking metformin for at least 1 month before diagnosis and 4 months after diagnosis. (DOCX $18 \mathrm{~kb}$ )

\section{Abbreviations}

ALR: Activity Level Reporting; AMPK: AMP-activated protein kinase; $\mathrm{Cl}$ : Confidence interval; $\mathrm{CIHI}$ : Canadian Institute for Health Information; CRT: Chemoradiotherapy; DSS: Disease-specific survival; HNSCC: Head and neck squamous cell carcinoma; HPV: Human Papillomavirus; HR: Hazards ratio; ODB: Ontario Drug Benefit Database; OHIP: Ontario Health Insurance Plan; ORGD: Office of the Registrar General Database; OS: Overall survival; RT: Radiation therapy; TNM: Tumor/node/metastases

\section{Acknowledgements}

None.

\section{Funding}

None.

\section{Availability of data and materials}

Data are available from the authors upon request.

\section{Authors' contributions}

A.E.Q. analyzed and interpreted data and drafted and edited the manuscript. N.L.L. analyzed and interpreted data and edited the manuscript. R.G. acquired data and edited the manuscript. S.H. participated in the design of the study, acquired data, and edited the manuscript. J.D. participated in the design of the study and edited the manuscript. S.J. conceived of the study, participated in the design of the study, and edited the manuscript. All authors read and approved the final manuscript.

\section{Ethics approval}

Not applicable.

\section{Consent for publication}

Not applicable.

\section{Competing interests}

The authors declare that they have no competing interests.

\section{Publisher's Note}

Springer Nature remains neutral with regard to jurisdictional claims in published maps and institutional affiliations.

\section{Author details}

${ }^{1}$ Department of Otolaryngology, Head and Neck Surgery, University of Ottawa, 501 Smyth Rd, Module S - Room M2566, Box 216, Ottawa, ON K1H 8L6, Canada. ${ }^{2}$ Institute for Clinical and Evaluative Sciences, Queen's University, Abramsky Hall, Room 208, 21 Arch Street, Kingston, ON K7L 3N6, Canada. ${ }^{3}$ Department of Otolaryngology, Head and Neck Surgery, Queen's University, 18 Barrie Street, Kingston, ON K7L 3N6, Canada. ${ }^{4}$ Ottawa Hospital Research Institute, 501 Smyth Rd, Box 511, Ottawa, ON K1H 8L6, Canada.

Received: 17 April 2018 Accepted: 22 November 2018 Published online: 04 December 2018

\section{References}

1. Canadian Cancer Society's Advisory Committee on Cancer Statistics. Canadian Cancer statistics 2015. Toronto, ON: Canadian Cancer Society; 2015.

2. Tan M, Sobel RH, Ha PK. Molecular biology of head and neck Cancer. In: Flint PW, Haughey BH, Lund VJ, et al., editors. Cummings otolaryngology head and neck surgery. Sixth ed: Elsevier; 2015. p. 1070-82.

3. Johnson-Obaseki S, McDonald JT, Corsten M, Rourke R. Head and neck cancer in Canada: trends 1992 to 2007. Otolaryngol -- Head Neck Surg 2012;147(1):74-8. https://doi.org/10.1177/0194599812437332.
4. Armstrong WB, Vokes DE, Verma SP. Malignant tumors of the larynx. In: Flint PW, Haughey BH, Lund VJ, et al., editors. Cummings otolaryngology head and neck surgery. Sixth ed. Philadelphia: Elsevier; 2015. p. 1601-13.

5. Tan L, Benign LT. Malignant tumors of the nasopharynx. In: Flint PW, Haughey $\mathrm{BH}$, Lund VJ, et al., editors. Cummings otolaryngology head and neck surgery. Sixth ed. Philadelphia: Elsevier; 2015. p. 1420-31.

6. Vila PM, Uppaluria R. Neoplasms of the hypopharynx and cervical esophagus. In: Flint PW, Haughey BH, Lund VJ, et al., editors. Cummings otolaryngology head and neck surgery. Sixth ed. Philadelphia: Elsevier. p. 1537-54.

7. De Boer MF, McCormick LK, Pruyn JF, Ryckman RM, van den Borne BW. Physical and psychosocial correlates of head and neck cancer: a review of the literature. Otolaryngol -- Head Neck Surg. 1999;120(3):427-36.

8. Myers JN, Chemotherapy KMS. Targeted biologic agents for head and neck squamous cell carcinoma. In: Flint PW, Haughey BH, Lund VJ, et al., editors. Cummings otolaryngology head and neck surgery. Sixth ed. Philadelphia: Elsevier; 2015. p. 1110-23.

9. Grandis JR, Tweardy DJ. Elevated levels of transforming growth factor alpha and epidermal growth factor receptor messenger RNA are early markers of carcinogenesis in head and neck cancer. Cancer Res. 1993;53:3579-84.

10. Kalyankrishna S, Grandis JR. Epidermal growth factor receptor biology in head and neck cancer. J Clin Oncol. 2006:24:2666-72.

11. Bonner JA, Harari PM, Giralt J, et al. Radiotherapy plus cetuximab for squamous-cell carcinoma of the head and neck. N Engl J Med. 2006;354: $567-78$.

12. Herbst RS. Erlotinib (Tarceva): an update on the clinical trial program. Semin Oncol. 2003;30:34-46.

13. Lee CK, Brown C, Gralla RJ, Hirsh V, Thongprasert S, Tsai CM, et al. Impact of EGFR inhibitor in non-small cell lung cancer on progression- free and overall survival: a meta-analysis. J Natl Cancer Inst. 2013;105:595-605.

14. Lebo NL, Griffiths R, Hall S, Dimitroulakos J, Johnson-Obaseki S. The effect of statin use on oncologic outcomes in head and neck squamous cell carcinoma. Under review - submitted. Head \& Neck. 2018;40(8):1697-1706.

15. Dimitroulakos J, Ye LY, Benzaquen $M$, et al. Differential sensitivity of various pediatric cancers and squamous cell carcinomas to lovastatin-induced Apoptosis: therapeutic implications differential sensitivity of various pediatric cancers and squamous cell carcinomas to lovastatin-induced apoptosis. Clin Cancer Res. 2001;7:158-67.

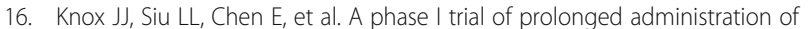
lovastatin in patients with recurrent or metastatic squamous cell carcinoma of the head and neck or of the cervix. Eur J Cancer. 2005:41(4):523-30.

17. Dayekh K, Johnson-Obaseki S, Corsten M, Villeneuve PJ, Sekhon HS, Weberpals Jl, Dimitroulakos J. Monensin inhibits epidermal growth factor receptor trafficking and activation: synergistic cytotoxicity in combination with EGFR inhibitors. Mol Cancer Ther. 2014;13(11):2559-71. https://doi.org/10.1158/1535-7163.MCT-13-1086.

18. Noto H, Osame K, Sasazuki T, Noda M. Substantially increased risk of cancer in patients with diabetes mellitus: a systematic review and meta-analysis of epidemiologic evidence in Japan. J Diabetes Complications. 2010;24:345-53.

19. Noto H, Tsujimoto T, Sasazuki T, Noda M. Significantly increased risk of Cancer in patients with diabetes mellitus. Endocr Pract. 2011;17:616-28.

20. Noto $\mathrm{H}$, Tsujimoto T, Noda M. Significantly increased risk of Cancer in diabetes mellitus patients: a meta-analysis of epidemiologic evidence in Asians and non-Asians. J Diabetes Investig. 2012:3(1):24-33.

21. Shaw RJ, Lamia KA, Vasquez D, et al. The kinase LKB1 mediates glucose homeostasis in liver and therapeutic effects of metformin. Science. 2005; 310:1642-6.

22. Bailey CJ, Turner RC. Metformin. N Engl J Med. 1996;334(9):574-9.

23. Corradetti MN, Inoki K, Bardeesy N, et al. Regulation of the TSC pathway by LKB1: evidence of a molecular link between tuberous sclerosis complex and Peutz-Jeghers syndrome. Genes Dev. 2004;18:1533-8.

24. Inoki K, Zhu T, Guan KL. TSC2 mediates cellular energy response to control cell growth and survival. Cell. 2003;115:577-90.

25. Shaw RJ, Bardeesy N, Manning BD, et al. The LKB1 tumor suppressor negatively regulates mTOR signaling. Cancer Cell. 2004;6:91-9.

26. Sanli T, Rashid A, Liu C, Harding S, Bristow RG, et al. lonizing radiation activates AMP-activate kinase (AMPK): a target for radiosensitization of human cancer cells. Int J Rad Onc Biol Phys. 2010;78(1):211-29.

27. Skinner HD, Sandulache VC, Ow TJ, Meyn RE, Yordy JS, Beadle BM, et al. TP53 disruptive mutations lead to head and neck cancer treatment failure through inhibition of radiation-induced senescence. Clin Cancer Res. 2012; 18:290-300. 
28. Noto H, Goto A, Tsujimoto T, Noda M. Cancer risk in diabetic patients treated with metformin: a systematic review and meta-analysis. PLoS One. 2012;7(3). https://doi.org/10.1371/journal.pone.0033411.

29. Evans JM, Donnelly LA, Emslie-Smith AM, Alessi DR, Morris AD. Metformin and reduced risk of cancer in diabetic patients. BMJ. 2005;330(7503):1304-5.

30. Bowker SL, Majumdar SR, Veugelers P, Johnson JA. Increased cancer-related mortality for patients with type 2 diabetes who use sulfonylureas or insulin. Diabetes Care. 2006;29(2):254-8.

31. Garrett $\mathrm{CR}$, Hassabo HM, N a B, et al. Survival advantage observed with the use of metformin in patients with type II diabetes and colorectal cancer. $\mathrm{Br}$ J Cancer. 2012;106(8):1374-8. https://doi.org/10.1038/bjc.2012.71.

32. Jiralerspong S. Metformin and pathologic complete responses to neoadjuvant chemotherapy in diabetic patients with breast cancer. J Clin Oncol. 2009;27: 3297-302 https://doi.org/10.1200/JCO.2009.19.6410.

33. Figueiredo RA, Weiderpass E, Tajara EH, Strom P, Carvalho A, et al. Diabetes mellitus, metformin and head and neck cancer. Oral Oncol. 2016;61:47-54.

34. Yen YC, Lin C, Lin SW, Lin YS, Weng SF. Effect of metformin on the incidence of head and neck cancer in diabetics. Head Neck. 2015;37(9):1268-73.

35. Sandulache VC, Hamblin JS, Skinner HD, Kubik MW, Myers JN, Zevallos JP. Association between metformin use and improved survival in patients with laryngeal squamous cell carcinoma. Head Neck. 2014:1039-43. https://doi. org/10.1002/HED.23409.

36. Canadian Pharmacists Association. Metformin HCl Canadian Pharmacists Association Monograph. Compendium of Pharmaceuticals and Specialties (CPS). https://pdf.hres.ca/dpd_pm/00021412.PDF. Published 2016. Accessed 6, Feb 2016

37. Lacchetti J, Waldron B, Perez-Ordonez S, Kamel-reid S, Gilbert R. Routine HPV Testing in Head and Neck Squamous Cell Carcinoma.; 2013.

38. Ragin CC, Taioli E. Survival of squamous cell carcinoma of the head and neck in relation to human papillomavirus infection: review and meta-analysis. Int J Cancer. 2007;121(8):1813-20.

39. Quan, et al. Coding algorithms for defining comorbidities in ICD-9-cm and ICD-10 administrative data. Med Care. 2005;43(11):1030-9.

40. Elixhauser A, Steiner C, Harris DR, Coffey RM. Comorbidity measures for use with administrative data. Med Care. 1998:36:8-27.

41. Garland A, Fransoo R, Olafson K, Ramsey C, Yogendran M, Chateau D, McGowan K. The epidemiology and outcomes of critical illness in Manitoba. Winnipeg, MB: Manitoba Centre for Health Policy, 2012.

42. Lieffers JR, Baracos VE, Winget M, Fassbender K. A comparison of Charlson and Elixhauser comorbidity measures to predict colorectal cancer survival using administrative health data. Cancer. 2011;117:1957-65.

43. Kaplan E, Meier P. Nonparametric estimation from incomplete observations. J Am Stat Assoc. 1958:53:457-81.

44. Rêgo DF, Pavan LM, Elias ST, De Luca Canto G, Guerra EN. Effects of metformin on head and neck cancer: a systematic review. Oral Oncol. 2015;51(5):416-22.

Ready to submit your research? Choose BMC and benefit from:

- fast, convenient online submission

- thorough peer review by experienced researchers in your field

- rapid publication on acceptance

- support for research data, including large and complex data types

- gold Open Access which fosters wider collaboration and increased citations

- maximum visibility for your research: over $100 \mathrm{M}$ website views per year

At $\mathrm{BMC}$, research is always in progress.

Learn more biomedcentral.com/submissions 